Acta Technologica Agriculturae 3

Nitra, Slovaca Universitas Agriculturae Nitriae, 2019, pp. 86-91

\title{
SELECTED PHYSICAL PROPERTIES ASSESSMENT OF SUNFLOWER AND OLIVE OILS
}

\author{
Peter HLAVÁČ ${ }^{*}$, Monika BOŽIKOVÁ, Ana PETROVIĆ \\ Slovak University of Agriculture in Nitra, Slovak Republic
}

\begin{abstract}
Presented paper is focused on comparison of certain physical properties of selected vegetable oils. Physical properties, such as density, dynamic, kinematic viscosity and fluidity, were experimentally determined. All experiments were conducted on two samples of vegetable oils: sunflower and extra virgin olive oils with approximate temperature range of $5-32{ }^{\circ} \mathrm{C}$. Density of oils was determined by oscillation method utilizing digital densimeter Anton Paar DMA 4500M at different temperatures. Dynamic viscosity was measured by means of rotational viscometer Anton Paar DV-3P. The rest of rheological parameters were determined on the basis of their definitions. Obtained results are depicted as graphical dependencies of rheological parameters and density on temperature. These dependencies of vegetable oils on dynamic and kinematic viscosity showed decreasing exponential shape, which is in compliance with Arrhenius equation; temperature dependencies on fluidity showed an increasing exponential shape for both samples. Density dependencies of samples on temperature were characteristic with decreasing linear function within measured temperature range. Similar results were achieved by other researchers. On the basis of measured values, it is evident that dynamic viscosity of extra virgin olive oil shows higher values than sunflower oil viscosity, which is a result of different composition of oils.
\end{abstract}

Keywords: sunflower oil; olive oil; physical parameters; temperature dependency; comparison

Accurate knowledge of physical quantities of materials represents an essential aspect in controlled processes in terms of manufacturing, handling, and holding. In order to assess the quality of food materials, it is vital to be familiar with physical properties of materials, especially mechanical, rheological and thermophysical characteristics (Božiková and Hlaváč, 2010).

This paper deals primarily with rheological properties that are considered to be complex material characteristics. Rheological properties have been measured for different food materials: milk (Hlaváč and Božiková, 2011; Kumbár and Nedomová, 2015), strawberry mash (Bukurov et al., 2012), quince puree (Bikić et al., 2012), chocolate (Glicerina et al., 2013; Kumbár et al., 2018), mixture of apple pomace and wheat flour (Diósi et al., 2014), honey (Hlaváč and Božiková, 2012), liquid egg products (Kumbár et al., 2015), wort (Hlaváč et al., 2016), etc. Viscosity is significant rheological property in terms of liquid products. It primarily affects the engine operation, since a higher fuel viscosity can result in malfunctions in feeding system and deposit formation in combustion chamber, filters, etc. (Corsini et al., 2015). Viscosity can be expressed as fluid resistance to flow and usually related physical unit to it is Pa.s. Temperature highly affects viscosity. Molecular structure causes the differences in temperature effect on viscosity of fluids and gases. With increment in temperature, it is possible to observe decreasing trend in liquid viscosity. Liquid molecules continuously move into the vacancies, and although this process allows the flow, it still requires energy (Bird et al., 1960). Fluid flows easily at higher temperatures and activation energy is better observable in such cases. Temperature impacts on viscosity can be expressed by means of an Arrhenius type equation (Eq. 1):

$$
\eta=\eta_{0} e^{-\frac{E_{A}}{R T}}
$$

where:

$\eta \quad$ - reference value of dynamic viscosity

$E_{A} \quad$ - activation energy

$R \quad$ - gas constant

$T \quad$ - absolute temperature (Figura and Teixeira, 2007)

Liquid molecules are closely spaced and attracted by strong cohesive forces and temperature impacts on viscosity can also be explained by these forces (Munson et al., 1994). Increase in temperature will cause decrease in these forces and liquid can flow more easily. Due to this fact, liquid viscosity decreases with temperature rise. Viscosity of majority of liquids is constant until the pressure reaches value of $10.134 \mathrm{MPa}$. However, by exceeding this value, viscosity increases with each increment in pressure (Sahin and Sumnu, 2006).

Ratio of dynamic viscosity $\eta$ to fluid density $\rho$ at identical temperature is called kinematic viscosity and can be expressed as follows:

$$
v=\frac{\eta}{\rho}
$$


Physical unit of this ratio is $\mathrm{m}^{2} \cdot \mathrm{s}^{-1}$. Reciprocal value of dynamic viscosity $\eta$ is fluidity $\varphi$ and its unit is $\mathrm{Pa}^{-1} \cdot \mathrm{s}^{-1}$.

$$
\varphi=\frac{1}{\eta}
$$

Oils extracted from plants have been utilized for millennia. Vegetable oil production includes oil removal from plant components - seeds in the majority of cases. This process can be performed either by mechanical or chemical extraction. The former is carried out by means of oil mill; the latter utilizes solvent. Subsequently, extracted oil is purified. Furthermore, it can be refined or chemically altered if necessary. Many vegetable oils are consumed directly or indirectly as ingredients in food. Moreover, they can be utilized in cooking of meals and this process includes their heating. Vegetable oils consist of triglycerides (Rafiq et al., 2015). Properties of different vegetable oils were examined by numerous authors. Stedile et al. (2015) compared physical properties and chemical composition of various bio-oils. Moser et al. (2009) analysed composition and physical properties of selected vegetable oils (cress, field pennycress and soybean). Impacts of composition on vegetable oils oxidation using differential scanning calorimetry was studied by Qi et al. (2016). Eight vegetable oils were subjected to examination: refined palm, olive, grapeseed, sunflower, corn, soybean, safflower and sesame oils. Activation energy of measured oils was also determined. Purification of vegetable oils by application of metal-organic frameworks was described by Vlasova et al. (2016). Authors found out that application of metal-organic frameworks enhances the physicochemical properties of unrefined vegetable oils (more pleasant taste and odour), because free fatty acids and peroxide compounds are bound in such manner. Selected physical properties of brominated vegetable oil as function of temperature were investigated by Thomas et al. (2015) They found out that it showed significantly higher values of density and dynamic viscosity than natural oils. This is probably a result of enhanced dispersion forces, rather than enhanced polarity upon bromination. Electrical properties of pumpkin seed oil were investigated by Prevc et al. (2015). They found out that typical roasted pumpkin seed oil shows higher electrical conductivity in contrast to unrefined extra virgin olive oils and refined sunflower oils. It is due to the fact that electrical conductivity tends to correlate with concentration of phospholipids and metals in oil. Pillai et al. (2016) have described structure, chemical composition and physical properties of metathesized palm oil and novel polyol derivatives. Kelly et al. (2014) have observed physical properties of spray-dried dairy powders mixed with various vegetable oils (sunflower oil, palm oil and its mixtures). Thermal properties of oils extracted from raspberry and blackberry seeds using differential scanning calorimetry were studied by Micić et al. (2014).

Vegetable oils are frequently included as an ingredient in multiple manufactured products. Vegetable oils functioning as additives in biodegradable films and coatings in terms of active food packaging were examined by Atarés and Chiralt (2016). Chen et al. (2014) have dealt with impacts of waste edible vegetable oil on rejuvenation of aged asphalt binders considering the physical, chemical and rheological properties. The results show that it can efficiently soften the aged asphalt. Both physical and rheological properties of aged asphalts can be improved to that of their original state if they are treated with optimum waste edible vegetable oil dosage. Bounding of masonry units with waste vegetable oil was analysed by Heaton et al. (2014). Physical quality and moisture content of wooden pellets blended with waste vegetable oil were analysed by Mišljenović et al. (2015). The results indicate that energy content of wooden pellets was significantly increased by adding oil. On the other hand, pellet strength was reduced by oil addition due to the lower friction on the pellet-die wall contact area. Padmini et al. (2016) have investigated a potential of vegetable-oil-based nanofluids as cutting fluids in machining. Production of alcohol from several vegetable oils was described by Dumont et al. (2013). Authors have also determined certain specific physical and chemical properties of obtained alcohols. Mello et al. (2013) have analysed certain low-toxic metal compounds produced during soybean oil polymerization in order to produce bio-based resins that could be exploited as a binder in printing inks.

Vegetable oils are frequently utilized as alternative fuels or lubricants. The tribological, rheological properties, as well as microstructure of oleogels on the basis of vegetable oils for lubrication purposes were analysed by MartínAlfonso and Valencia (2015). Emberger et al. (2015) have studied chemical composition and physical properties of ten vegetable oils (coconut, palm, high oleic sunflower, rapeseed, sunflower, camelina, linseed, soybean, corn, jatropha). Furthermore, they also investigated their ignition and combustion behaviour after injecting them into a constant volume combustion chamber. Ashraful et al. (2014) have compared fuel and emission properties, as well as engine performance characteristics of biodiesel fuels made of several non-edible vegetable oils (karanja, polanga, mahua, rubber seed, cotton seed, jojoba, tobacco neem, linseed and jatropha). Various biodiesel types with different vegetable oils (soybean, rapeseed, mustard, canola, palm, sunflower, rice bran, jatropha, karanja and used cooking oil) have been analysed by Issariyakul and Dalai (2014). Electrochemical impedance spectroscopy was utilized in research of biodiesel fuels made of different vegetable oils (canola, soybean, sunflower, and corn) by M'Peko et al. (2013). Authors have presented correlations between electric properties (resistivity and dielectric constant) and dynamic viscosity. Utilization of vegetable oils as a fuel in burners was studied by San José et al. (2015). During the investigation, authors used four vegetable oils made of rapeseed, soya, sunflower and refined seed. For the optimal combustion process, knowledge of physical properties (density, viscosity, etc.) and composition of the fatty acids is essential. Cermak et al. (2013) have compared properties of oils made of modern crops (lesquerella, field pennycress, meadowfoam and cuphea) with common commodity vegetable oils. They found out that all oils showed unique preconditioning them for lubrication purposes. Certain blended aviation biofuels made primarily of esterified Jatropha curcas with addition of waste vegetable oils were analysed by Baroutian et al. (2013). 


\section{Material and methods}

Measurements were carried out under laboratory regime (temperature $-20{ }^{\circ} \mathrm{C}$; atmospheric pressure $-1,013 \mathrm{hPa}$; relative air humidity - $45 \%$ ) on two samples of vegetable oil purchased at local market. The first sample was sunflower oil and other one was extra virgin olive oil. Rheological parameters - dynamic viscosity, kinematic viscosity, fluidity and density - were subjected to analyses during experiments. At first, samples were cooled to temperature of $3{ }^{\circ} \mathrm{C}$. Subsequently, dynamic viscosity and density were measured at particular temperature values during the temperature stabilisation in approximate temperature range $5-32{ }^{\circ} \mathrm{C}$. Dynamic viscosity was recorded utilizing digital rotational viscometer Anton Paar (DV-3P). This device works on principle founded on dependency of sample resistance to the probe rotation. Moreover, density of vegetable oils was measured utilizing densimeter Anton Paar DMA $4500 \mathrm{M}$ and was recorded at the same temperatures as dynamic viscosity. Together with recorded dynamic viscosity values, obtained density values were utilized in kinematic viscosity calculation (Eq. 2). Reciprocal value of dynamic viscosity (fluidity) was also determined (Eq. 3). Correlations between rheological parameters and temperature were observed and properties of vegetable oils were compared.

It is possible to depict the temperature dependencies of dynamic viscosity for observed oils in form of decreasing exponential functions (Eq. 4). The same is true for temperature dependencies of kinematic viscosity (Eq. 5). Considering the temperature dependencies of fluidity, trends can be shown by increasing exponential functions (Eq. 6). Decreasing linear function (Eq. 7) described the trends in terms of temperature dependencies of density:

$$
\begin{gathered}
\eta=A e^{-B\left(\frac{t}{t_{0}}\right)} ; v=C e^{-D\left(\frac{t}{t_{0}}\right)} ; \\
\varphi=E e^{F\left(\frac{t}{t_{0}}\right)} ; \rho=-G\left(\frac{t}{t_{0}}\right)+H
\end{gathered}
$$

where:

$t \quad$ - temperature

$t_{o}-1{ }^{\circ} \mathrm{C} ; A, B, C, D, E, F, G, H$ - constants dependent on material type and methods of processing and storage

\section{Results and discussion}

Considering the vegetable oils dynamic viscosity and density, obtained temperature dependencies of observed vegetable oils are shown in Fig. 1 and Fig. 2. It is evident from Fig. 1 that dynamic viscosity of oils shows decreasing trends with increments in temperature. It is possible to visualise this progress by means of decreasing exponential function, which is in compliance with Arrhenius equation (Eq. 1). Similar conclusions were made by authors Diamante and Lan (2014) and Thomas et al. (2015). Regression coefficients and coefficients of determination are shown in Table 1. Furthermore, Fig. 1 shows that values of dynamic viscosity of extra virgin olive oil were higher than those of sunflower oil, which could have been caused by different composition of oils.

Dependencies of oil density on temperature are presented in Fig. 2. It is evident that values of density are decreasing with increasing temperature for both samples. Linear decreasing function was utilized for description of the progress at given temperature range. Thomas et al. (2015) deployed the identical dependency type. Density of sunflower oil was higher in contrast to extra virgin olive oil sample. Similar results for sunflower oil were obtained by Emberger et al. (2015), San José et al. (2015), and for olive oil by Tanilgan et al. (2007).

\begin{tabular}{|c|c|c|c|}
\hline \multirow[b]{3}{*}{ Sample } & \multicolumn{3}{|c|}{ Regression equations $(4,5,6,7)$} \\
\hline & \multicolumn{3}{|c|}{ Coefficients } \\
\hline & $A(m P a \cdot s)$ & B (1) & $R^{2}$ \\
\hline Sunflower oil & 251.491 & 0.028017 & 1.000000 \\
\hline Olive oil & 261.117 & 0.022905 & 0.999958 \\
\hline Sample & $C\left(\mathrm{~mm}^{2} \cdot \mathrm{s}^{-1}\right)$ & $D(1)$ & $R^{2}$ \\
\hline Sunflower oil & 269.187 & 0.027260 & 0.999999 \\
\hline Olive oil & 281.934 & 0.022151 & 0.999960 \\
\hline Sample & $E\left(\mathrm{~Pa}^{-1} \cdot \mathrm{s}^{-1}\right)$ & $F(1)$ & $R^{2}$ \\
\hline Sunflower oil & 3.98038 & 0.027965 & 0.999996 \\
\hline Olive oil & 3.82843 & 0.0229206 & 0.999937 \\
\hline Sample & $H\left(\mathbf{k g} \cdot \mathrm{m}^{-3}\right)$ & $G\left(\mathbf{k g} \cdot \mathrm{m}^{-3}\right)$ & $R^{2}$ \\
\hline Sunflower oil & 933.866 & 0.682059 & 0.999997 \\
\hline Olive oil & 926.042 & 0.684142 & 0.999996 \\
\hline
\end{tabular}

Table 1 Coefficients A, B, C, D, E, F, G, H of regression equations $(4,5,6$ and 7$)$ and coefficients of determinations $\left(R^{2}\right)$ 


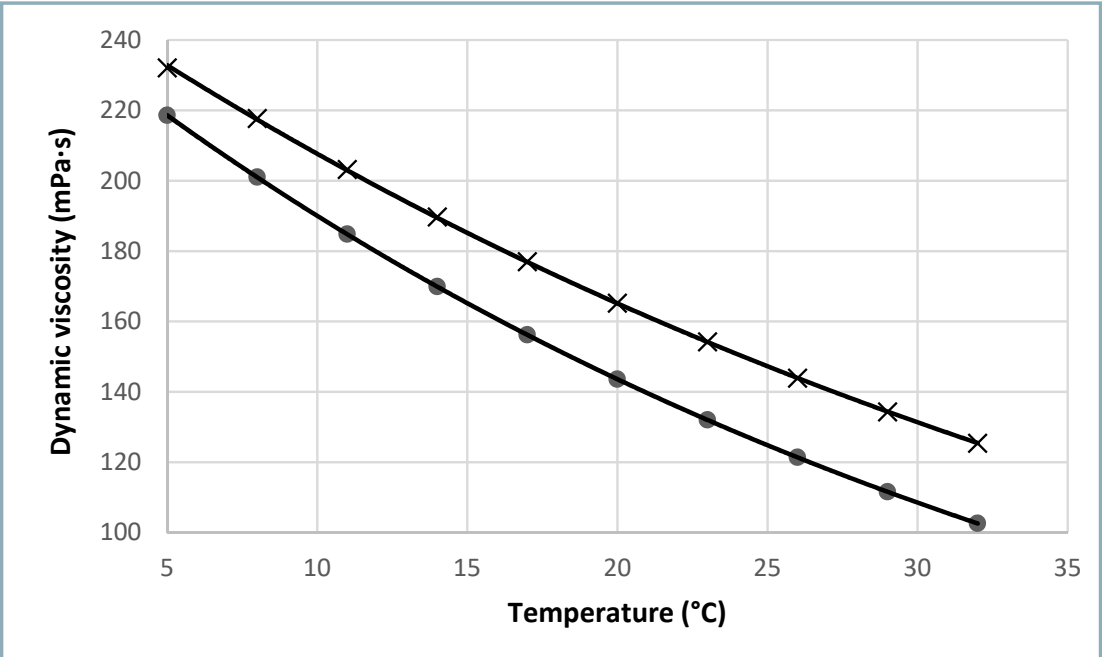

Fig. 1 Temperature dependencies of dynamic viscosity for vegetable oils - - sunflower oil; $x$ - extra virgin olive oil

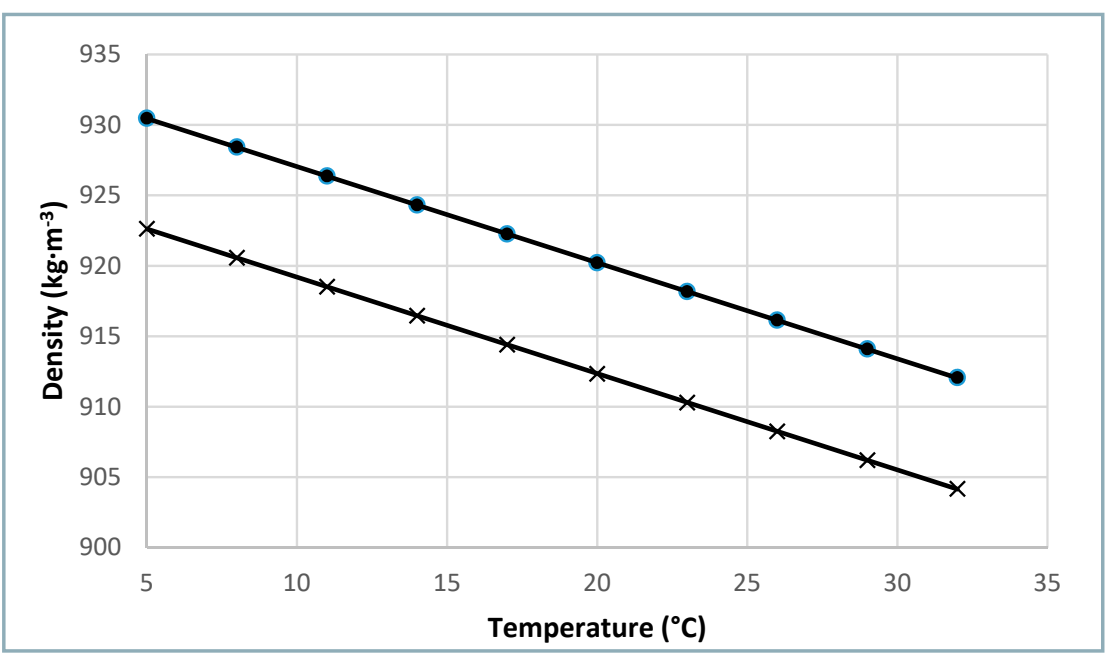

Fig. 2 Temperature dependencies of density for vegetable oils - - sunflower oil; $x$ - extra virgin olive oil

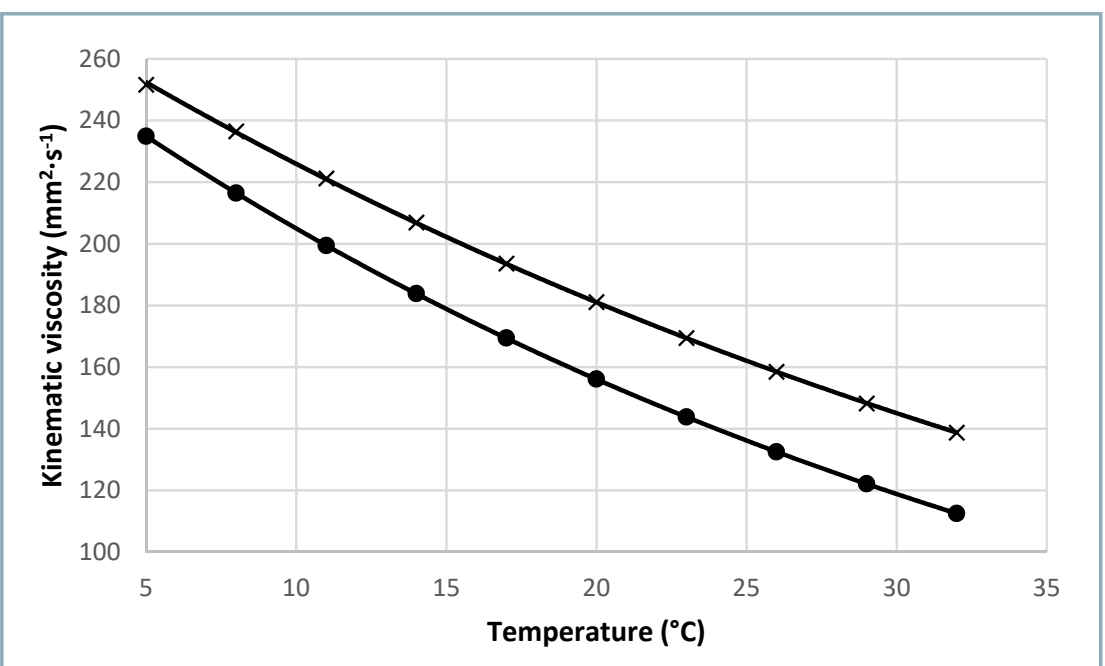

Fig. 3 Temperature dependencies of kinematic viscosity for vegetable oils - - sunflower oil; $x$ - extra virgin olive oil
Fig. 3 and Fig. 4 depict temperature dependencies of kinematic viscosity and fluidity observed in analysed samples. For both samples, decreasing function describes dependencies of kinematic viscosity on temperature. Table 1 provides values of regression coefficients and coefficients of determination. In contrast to extra virgin olive oil, sunflower oil showed higher values of kinematic viscosity (Fig. 3). This is most likely due to same reason as in case of dynamic viscosity. Temperature dependencies of fluidity are depicted in Fig. 4. It is obvious that with increase in temperature, there is also an increase in fluidity. Ultimately, Table 1 provides values of regression coefficients and coefficients of determination. It is possible to explain the proportion of curves shown in Fig. 4 in similar manner as in previous dependencies.

It is evident from Table 1 that coefficients of determinations showed very high values in the given range (0.99993-1.0) in all cases.

\section{Conclusion}

Physical properties of food materials must be analysed individually due to the very complex composition of these materials. Properties of these materials can be influenced in multiple ways (e.g. manipulation, external conditions, etc.). Rheological properties of selected vegetable oils were observed and subjected to analysis in this paper. Impacts of temperature on measured samples of vegetable oils were investigated and their properties were compared.

In terms of dynamic and kinematic viscosities, temperature dependencies of vegetable oils had decreasing shape (Fig. 1 and Fig. 3). Considering the temperature dependencies of fluidity, there have been observed an increasing shape (Fig. 4). In order to stay in line with Arrhenius equation (1), exponential functions were utilized for expression of temperature dependencies of rheological properties. Similar results were also achieved by other authors (Diamante and Lan, 2014; Thomas et al., 2015).

Linear decreasing functions were utilized for expression of temperature dependencies of density for observed oils in the given temperature range (Fig. 2). Several other authors 


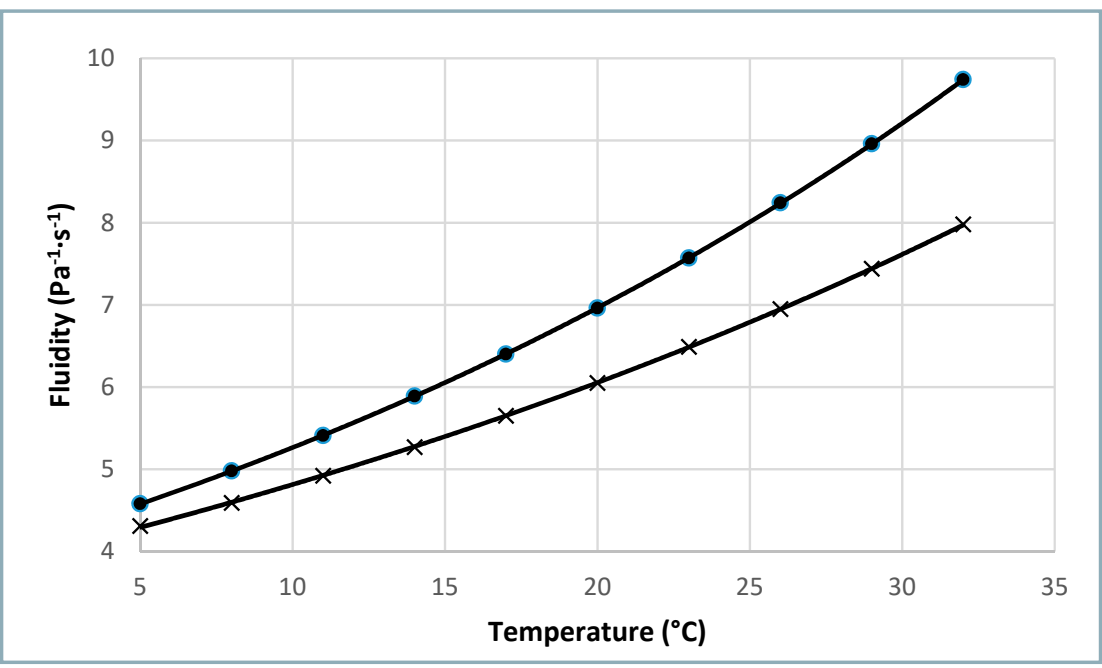

Fig. 4 Temperature dependencies of fluidity for vegetable oils - - sunflower oil; $x$ - extra virgin olive oil

(Emberger et al., 2015; San José et al., 2015; Tanilgan et al., 2007) achieved similar results for density of vegetable oils.

It was observed that values of dynamic and kinematic viscosities for extra virgin olive oil were higher than for sunflower oil, which could have been caused by different composition of oils. Fluidity and density of extra virgin olive oil showed lower values most likely for the same reason as well.

\section{Acknowledgements}

This work was supported by the project of KEGA 017 SPU-4/2017 of Ministry of Education, Science, Research, and Sport of the Slovak Republic and also co-funded by the European Community under the project No 26220220180: Building the Research Centre AgroBioTech.

\section{References}

ASHRAFUL, A. M. - MASJUKI, H. H. KALAM, M. A. - RIZWANUL FATTAH, I. M. IMTENAN, S. - SHAHIR, S. A. - MOBARAK, H. M. 2014. Production and comparison of fuel properties, engine performance, and emission characteristics of biodiesel from various non-edible vegetable oils: A review. In Energy Conversion and Management, vol. 80, pp. 202-228.

ATARÉS, L. - CHIRALT, A. 2016. Essential oils as additives in biodegradable films and coatings for active food packaging. In Trends in Food Science \& Technology, vol. 48, pp. 51-62.

BAROUTIAN, S. - AROUA M. K. - RAMAN, A. A. A. - SHAFIE, A. - ISMAIL, R. A. HAMDAN, H. 2013. Blended aviation biofuel from esterified Jatropha curcas and waste vegetable oils. In Journal of the Taiwan Institute of Chemical Engineers, vol. 44, pp. 911-916.

BIKIĆ, S. - BUKUROV, M. - BABIĆ, M. PAVKOV, I.-RADOJČIN, M. 2012. Rheological behavior of quince (Cydonia oblonga) puree. In Journal on Processing and Energy in Agriculture, vol. 16, no. 4, pp. 155-161.

BIRD, R. B. - STEWART, W. E. - LIHGTFOOT, E. N. 1960. Transport Phenomena. New York: John Wilie \& Sons.

BOŽIKOVÁ, M. - HLAVÁČ, P. 2010. Selected physical properties of agricultural and food products. Nitra: SUA in Nitra, 2010, 178 pp. (scientific monograph)

BUKUROV, M. - BIKIĆ, S. - BABIĆ, M. - PAVKOV, I. - RADOJČIN, M. 2012. Rheological behavior of Senga Sengana strawberry mash. In Journal on Processing and Energy in Agriculture, vol. 16, no. 4, pp. 142-146.

CERMAK, S. C. - BIRESAW, G. - ISBELL, T. A. - EVANGELISTA, R. L. - VAUGHN, S. F. MURRAY, R. 2013. New crop oils - Properties as potential lubricants. In Industrial Crops and Products, vol. 44, pp. 232-239.

CHEN, M. - LENG, B. - WU, S. - SANG, Y. 2014. Physical, chemical and rheological properties of waste edible vegetable oil rejuvenated asphalt binders. In Construction and Building Materials, vol. 66, pp. 286-298.

CORSINI, A. - MARCHEGIANI, A. - RISPOLI, F. - SCIULLI, F. - VENTURINI, P. 2015. Vegetable oils as fuels in diesel engine. Engine performance and emissions. In Energy Procedia, vol. 81, pp. 942-949.

DIAMANTE, L. M. - LAN, T. 2014. Absolute viscosities of vegetable oils at different temperatures and shear rate range of 64.5 to $4835 \mathrm{~s}^{-1}$. In Journal of Food Processing, Article ID 234583, 6 p. doi:10.1155/2014/234583.
DIÓSI, G. - MÓRÉ, M. - SIPOS, P. 2014. Rheological properties of the mixture product of apple pomace and wheat flour. In Journal on Processing and Energy in Agriculture, vol. 18, no. 4, pp. 151-153.

DUMONT, M. J. - KHARRAZ, E. - QI, H. 2013. Production of polyols and monools from 10 North-American vegetable oils by ozonolysis and hydrogenation: A characterization study. In Industrial Crops and Products, vol. 49, pp. 830-836.

EMBERGER, P. - HEBECKER, D. - PICKEL, P. REMMELE, E. - THUNEKE, K. 2015. Ignition and combustion behaviour of vegetable oils after injection in a constant volume combustion chamber. In Biomass and Bioenergy, vol. 78, pp. 48-61.

FIGURA, L. O. - TEIXEIRA, A. A. 2007. Food Physics, Physical Properties - Measurement and Applications. USA: Springer. 550 pp.

GLICERINA, V. - BALESTRA, F. - DALLA ROSA, M. - ROMANI, S. 2013. The influence of process steps on microstructural, rheological and thermal properties of dark chocolate. In Journal on Processing and Energy in Agriculture, vol. 17, no. 2, pp. 59-63.

HEATON, T. - SAMMON, C. - AULT, J. BLACK, L. - FORTH, J. P. 2014. Masonry units bound with waste vegetable oil - Chemical analysis and evaluation of engineering properties. In Construction and Building Materials, vol. 64, pp. 460-472.

HLAVÁČ, P. - BOŽIKOVÁ, M. 2011. Effect of temperature on milk rheologic and thermophysical properties. In Journal on Processing and Energy in Agriculture, vol. 15, no. 1, pp. 17-22.

HLAVÁČ, P. - BOŽIKOVÁ, M. 2012. Influence of temperature and storing time on flower honey rheologic and thermophysical properties. In Journal on Processing and Energy in Agriculture, vol. 16, no. 2, pp. 52-56.

HLAVÁČ, P. - BOŽIKOVÁ, M. - CVIKLOVIČ, V. 2016. Dynamic viscosity and activation energy of wort during fermentation and storing. In Acta Technologica Agriculturae, vol. 19, no. 1, pp. 6-9.

ISSARIYAKUL, T. - DALAI, A. K. 2014. Biodiesel from vegetable oils. In Renewable and Sustainable Energy Reviews, vol. 31, pp. 446-471.

KELLY, G. M. - O'MAHONY, J. A. - KELLY, A. L. - O'CALLAGHAN, D. J. 2014. Physical characteristics of spray-dried dairy powders containing different vegetable oils. In Journal of Food Engineering, vol. 122, pp. 122-129.

KUMBÁR, V. - NEDOMOVÁ, Š. 2015. Viscosity and analytical differences between raw milk and UHT milk of Czech cows. In Scientia Agriculturae Bohemica, vol. 46 , pp. 78-83. 
KUMBÁR, V. - TRNKA, J. - NEDOMOVÁ, Š. - BUCHAR, J. 2015. On the influence of storage duration on rheological properties of liquid egg products and response of eggs to impact loading - Japanese quail eggs. In Journal of Food Engineering, vol. 166, pp. 86-94.

KUMBÁR, V. - NEDOMOVÁ, Š. - ONDRUŠíKOVÁ, S. - POLCAR, A. 2018. Rheological behaviour of chocolate at different temperatures. In Potravinárstvo, vol. 12, no. 1, pp. 123-128.

MARTíN-ALFONSO, J. E. - VALENCIA, C. 2015. Tribological, rheological, and microstructural characterization of oleogels based on EVA copolymer and vegetables oils for lubricant applications. In Tribology International, vol. 90, pp. 426-434.

MELLO, V. M. - OLIVEIRA, G. V. - MANDARINO, J. M. G. - CARRĂOPANIZZI, M. C. - SUAREZ, P. A. Z. 2013. New metal catalysts active for thermal polymerization of vegetable oils. In Industrial Crops and Products, vol. 43, pp. 56-60.

MICIĆ, D. - OSTOJIĆ, S. - SIMONOVIĆ, M. - SIMONOVIĆ, B. R. 2014. Thermal behavior of raspberry and blackberry seeds oils followed by DSC. In Journal on Processing and Energy in Agriculture, vol. 18, no. 5, pp. 204-206.

MIŠLJENOVIĆ, N. - MOSBYE, J. - SCHÜLLER, R. B. - LEKANG, O. I. SALAS-BRINGAS, C. 2015. Physical quality and surface hydration properties of wood based pellets blended with waste vegetable oil. In Fuel Processing Technology, vol. 134, pp. 214-222.

MOSER, B. R. - SHAH, S. N. - WINKLER-MOSER, J. K. - VAUGHN, S. F. - EVANGELISTA, R. L. 2009. Composition and physical properties of cress (Lepidium sativum L.) and field pennycress (Thlaspi arvense L.) oils. In Industrial Crops and Products, vol. 30, pp. 199-205.

M'PEKO, J. C. - REIS, D. L. S. - DE SOUZA, J. E. - CAIRES, A. R. L. 2013. Evaluation of the dielectric properties of biodiesel fuels produced from different vegetable oil feedstocks through electrochemical impedance spectroscopy. In International Journal of Hydrogen Energy, vol. 38, pp. 9355-9359.

MUNSON, B. R. - YOUNG, D. F. - OKIISHI, T. H. 1994. Fundamentals of Fluid Mechanics. New York: John Wilie \& Sons.

PADMINI, R. - KRISHNA, P. V. - RAO, G. K. M. 2016. Effectiveness of vegetable oil based nanofluids as potential cutting fluids in turning AISI 1040 steel. In Tribology International, vol. 94, pp. 490-501.

PILLAI, P. K. S. - LI, S. - BOUZIDI, L. - NARINE, S. S. 2016. Metathesized palm oil \& novel polyol derivatives: Structure, chemical composition and physical properties. In Industrial Crops and Products, vol. 84, pp. 205-223.
PREVC, T. - SEGATIN, N. - KRALJ, P. - ULRIH, N. P. - CIGIĆ, B. 2015. Influence of metal ions and phospholipids on electrical properties: A case study on pumpkin seed oil. In Food Control, vol. 54, pp. 287-293.

QI, B. - ZHANG, Q. - SUI, X. - WANG, Z. - LI, Y. - JIANG, L. 2016. Differential scanning calorimetry study - Assessing the influence of composition of vegetable oils on oxidation. In Food Chemistry, vol. 194, pp. 601-607.

RAFIQ, M. - LV, Y. Z. - ZHOU, Y. - MA, K. B. - WANG, W. - LI, C. R. WANG, Q. 2015. Use of vegetable oils as transformer oils - a review. In Renewable and Sustainable Energy Reviews, vol. 52, pp. 308-324. SAHIN, S. - SUMNU, S. G. 2006. Physical Properties of Foods. USA: Springer, $257 \mathrm{pp}$.

SAN JOSÉ, J. - SANZ-TEJEDOR, M. A. - ARROYO, Y. 2015. Effect of fatty acid composition in vegetable oils on combustion processes in an emulsion burner. In Fuel Processing Technology, vol. 130, pp. 20-30.

STEDILE, T. - ENDER, L. - MEIER, H. F. - SIMIONATTO, E. L. WIGGERS, V. R. 2015. Comparison between physical properties and chemical composition of bio-oils derived from lignocellulose and triglyceride sources. In Renewable and Sustainable Energy Reviews, vol. 50, pp. 92-108.

TANILGAN, K. - ÖZCAN, M. M. - ÜNVER, A. 2007. Physical and chemical characteristics of five Turkish olive (Olea europea L.) varieties and their oils. In Grasas y Aceites, vol. 58, no. 2, pp. 142-147.

THOMAS, M. J. - BRAMBLETT, K. A. - GREEN, B. D. - WEST, K. N. 2015. Thermophysical and absorption properties of brominated vegetable oil. In Journal of Molecular Liquids, vol. 211, pp. 647-655.

VLASOVA, E. A. - YAKIMOV, S. A. - NAIDENKO, E. V. - KUDRIK, E. V. - MAKAROV, S. V. 2016. Application of metal-organic frameworks for purification of vegetable oils. In Food Chemistry, vol. 190, pp. 103-109. 